\title{
Urgences
}

\section{La métaphore onirique}

\section{Johanne Lepage}

Numéro 29, octobre 1990

\section{Éclats d'œuvre}

URI : https://id.erudit.org/iderudit/025604ar

DOI : https://doi.org/10.7202/025604ar

Aller au sommaire du numéro

Éditeur(s)

Urgences

\section{ISSN}

0226-9554 (imprimé)

1927-3924 (numérique)

Découvrir la revue

Citer ce document

Lepage, J. (1990). La métaphore onirique. Urgences, (29), 56-57.

https://doi.org/10.7202/025604ar d'utilisation que vous pouvez consulter en ligne.

https://apropos.erudit.org/fr/usagers/politique-dutilisation/ 


\section{La métaphore onirique Johanne Lepage}

Cathédrale. Ce mot lancé en plein atelier l'autre jour a fait surgir l'image de l'oubli: à deux étapes précises de mon livre, j'avais rêvé du bâtiment sans en reconnaître l'architecture, entièrement placardée. La première fois, j’étais tout juste à quelques jours d'en jeter la phrase initiale. La seconde, un bon pan de récit était prêt, je l'avais imprimé l'après-midi, et j'estimais, assez fière, l'ardeur de mon travail au poids du papier. Ce soir-là, j'avais reconnu la tour sombre du clocher et sa croix de fer contre un nuage phosphorescent. Des placards étaient tombés de la métaphore inconsciente.

Oubli, inconscient. Deux termes qui appartiennent à la nuit de l'être. Qui sont à la fois ses origines et son néant à venir. Qu'y aurait-il d'autre entre ces deux nuits de commencement, de fin du monde, sinon une quête avide de lumière? Sinon une conscience émergeant au jour par et dans l'œuvre? Ainsi, c'est par et dans l'œuvre (dans son sens élargi à l'action) que nous existons. CEuvrer (agir), c'est être.

L'œuvre, c'est encore l'identité multiple dans l'être unique : identité sociale, identité culturelle, identité historique... Autant de consciences aiguës émergent, s'élevant jusqu'à elle pour s'y révéler, principe unifiant de l'humaine complexité. Cuvre est donc entité. Aussi dirai-je, par laçage de mots et les extrapolant jusqu'au dernier degré de l'échelle, reportant l'œuvre dans la culture, reportant l'être dans l'humanité, que l'œuvre éclaire l'être comme la culture éclaire l'humanité, que l'œuvre éclaire l'humanité comme la culture éclaire l'être. Finalement, que les premières - œuvre et culture donnent de l'âme aux seconds - être et humanité.

L'idée de lumière, c'est encore de la cathédrale rêvée qu'elle vient. Je l'ai dit déjà, je n'en ai pas tout de suite reconnu l'architecture, gigantesque amas barricadé, monument aux graffiti enchâssés dans l'opacité, la désolation du silence, dans la nuit la plus noire comme le sont les nuits sans étoiles.

En cachette, et non sans frayeur d'être vue - la création de l'œuvre est au secret ce que la création de l'être est au mystère -, je me suis faufilée jusqu'à sa lourde porte par 
une galerie d'interstices tout juste assez larges pour laisser glisser mon ombre de profil. De tout mon poids, j'ai tiré à deux mains sur l'anneau rouillé. À l'intérieur, la cathédrale n'était pas illuminée mais enluminée. Ajoutant la dorure à la lumière, l'art à l'être. 